\title{
Intraoperative breakage of Sachse's knife blade: a rare complication of optical internal urethrotomy (one case managing experience)
}

Gautam Kumar Kanodia ${ }^{1}$, Satyanarayan Sankhwar ${ }^{1}$, Ankur Jhanwar ${ }^{1}$, Ankur Bansal ${ }^{1}$, Manoj Kumar ${ }^{1}$, Ashok Gupta ${ }^{1}$

${ }^{1}$ King George Medical University, Lucknow, Uttar Pradesh, India

\section{ABSTRACT}

Optical internal urethrotomy (OIU) is the most common procedure performed for short segment bulbar urethral stricture worldwide. This procedure most commonly performed using Sachse's cold knife. Various perioperative complications of internal urethrotomy have been described in literature including bleeding, urinary tract infection, extravasation of fluid, incontinence, impotence, and recurrence of stricture. Here we report a unique complication of breakage of Sachse knife blade intraoperatively and its endoscopic management.

\section{ARTICLE INFO}

Keywords:

Urethra; Recurrence; Methods

Int Braz J Urol. 2017; 43: 163-5

Submitted for publication:

February 01, 2016

Accepted after revision:

March 13, 2016

Published as Ahead of Print: October 03, 2016

\section{INTRODUCTION}

Optical internal urethrotomy (OIU) is the most common procedure performed for short segment bulbar urethral stricture worldwide (1). However, its success rate is variable, and ranges from $35-60 \%(2,3)$. This procedure is most commonly performed using Sachse's cold knife (4), although recently lasers have been introduced in the urological armamentarium for internal urethrotomy. Various perioperative complications of internal urethrotomy have been described in literature, including bleeding, urinary tract infection, extravasation of fluid, incontinence, impotence, and recurrence of stricture (5). Here we report a unique complication of breakage of Sachse knife blade intraoperatively and its endoscopic management.

\section{Case Report}

A 30 year-old male presented with complaint of lower urinary tract symptoms for the last six months. Uroflowmetry voiding pattern was suggestive of urethral stricture disease. Retrograde urethrography (RGU) revealed a short segment bulbar urethral stricture $(<1.5 \mathrm{cms})$. Optical internal urethrotomy was performed. Intraoperatively blade of Sachse's urethrotome accidently broken and fell proximal to the stricture which was 
Figure 1 - Fluroscopic view of broken blade in bulbar urethra.

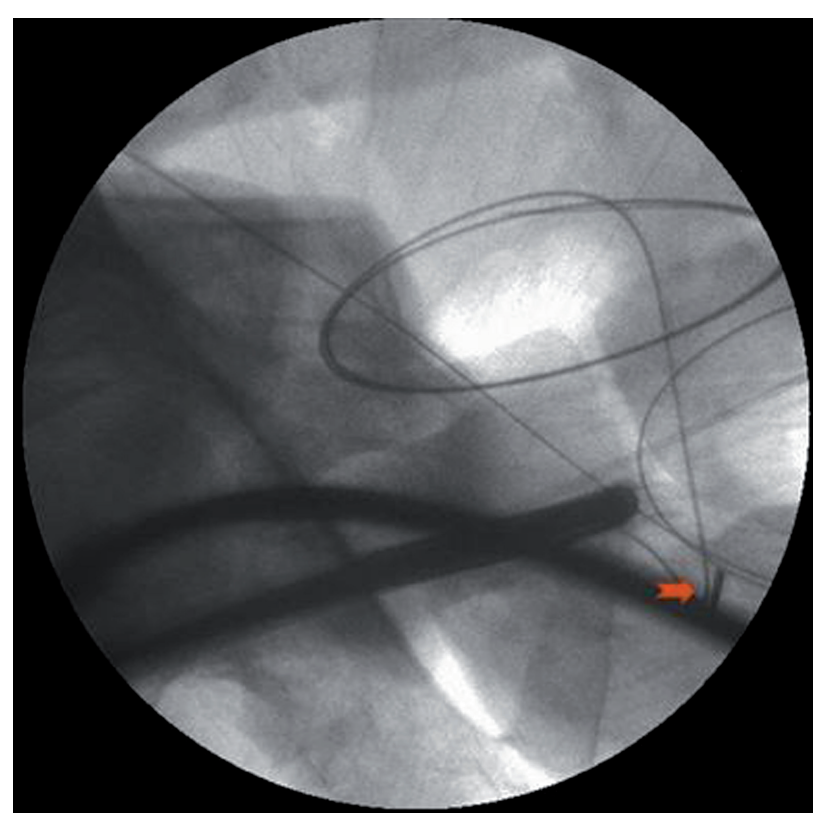

confirmed on fluoroscopy (Figure-1). We completed the procedure with another working element. During the procedure broken blade migrated to bladder (Figure-2). We retrieved the blade into the cystoscope sheath (22Fr) with the help of double $\mathrm{J}$ stent removing forceps. Cystoscope, sheath, forceps and the broken blade were withdrawn from the urethra as a single unit (Figure-3).

Figure 2 - Cystoscopic view of holding broken blade with Double $\mathrm{J}$ removal forceps.

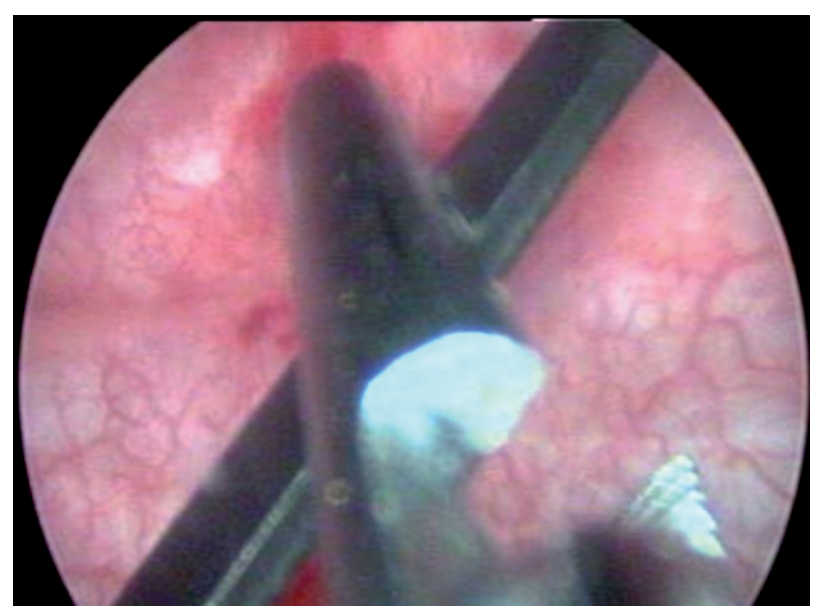

Figure 3 - Removal of knife blade.

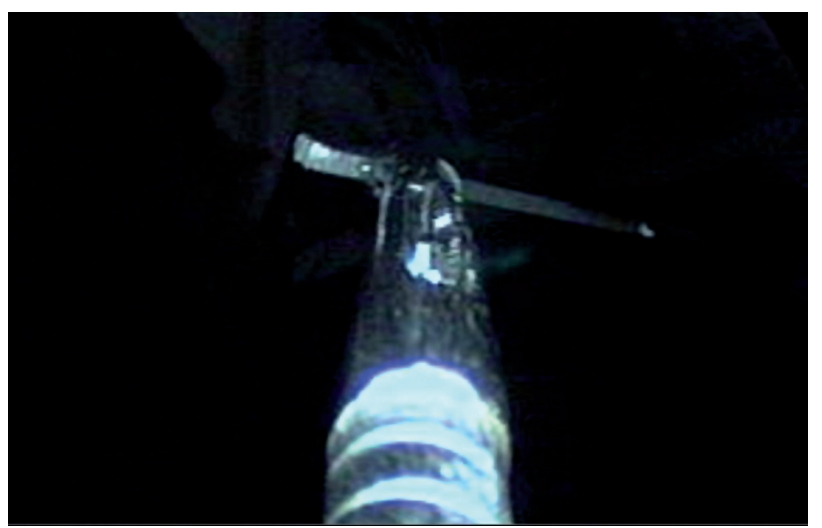

\section{DISCUSSION}

Optical internal urethrotomy became popularized after the work of Sachse in 1971 (6) and now it is the preferred treatment modality for a short segment urethral stricture. This is the most favored procedure among the urologist as it is less morbid and minimally invasive day care surgery which is appealing to both patient and surgeon. The most common complications are recurrence of the stricture and bleeding $(7,8)$. The purpose of this case report is to highlight the unique complication of intraoperative breakage of knife blade and its endoscopic management. One should not start this (neither any other) procedure not being prepared to all its complications and that blade breakage is one of these, making necessary a blade backup and a double-J forceps available before starting this procedure. To the best of our knowledge, this is the only case report which describe this unique complication and management.

\section{CONCLUSIONS}

This complication should be kept in mind and instruments should be checked properly by the operative surgeon prior to start the procedure. Retained sharp objects like knife blade in urethra as a result of breakage of Sachse knife blade can be managed endoscopically.

\section{CONFLICT OF INTEREST}

None declared. 


\section{REFERENCES}

1. Greenwell TJ, Castle C, Andrich DE, MacDonald JT, Nicol DL, Mundy AR. Repeat urethrotomy and dilation for the treatment of urethral stricture are neither clinically effective nor cost-effective. J Urol. 2004;172:275-7.

2. Wright JL, Wessells $H$, Nathens $A B$, Hollingworth W. What is the most cost-effective treatment for 1 to $2-\mathrm{cm}$ bulbar urethral strictures: societal approach using decision analysis. Urology. 2006;67:889-93.

3. Rourke KF, Jordan GH. Primary urethral reconstruction: the cost minimized approach to the bulbous urethral stricture. J Urol. 2005;173:1206-10.
4. Dubey D. The current role of direct vision internal urethrotomy and self-catheterization for anterior urethral strictures. Indian J Urol. 2011;27:392-6.

5. Hussain M, Lal M, Askari SH, Hashmi A, Rizvi SA. Holmium laser urethrotomy for treatment of traumatic stricture urethra: a review of 78 patients. J Pak Med Assoc. 2010;60:829-32.

6. Sachse H. [Treatment of urethral stricture: transurethral slit in view using sharp section]. Fortschr Med. 1974;92:12-5.

7. Pansadoro V, Emiliozzi P. Internal urethrotomy in the management of anterior urethral strictures: long-term followup. J Urol. 1996;156:73-5.

8. Chilton CP, Shah PJ, Fowler CG, Tiptaft RC, Blandy JP. The impact of optical urethrotomy on the management of urethral strictures. Br J Urol. 1983;55:705-10.

Correspondence address:

Gautam Kumar Kanodia, MD

Department of urology

King George Medical University, Lucknow

Uttar Pradesh, India, 226003

Telephone: + 9176 0784-8665

E-mail: drgautam_mumbai@rediffmail.com 